\title{
GAMBARAN PENGETAHUAN SIKAP DAN PERILAKU PENGUNJUNG DALAM PENGELOLAAN SAMPAH DI PANTAI MERTASARI TAHUN 2020
}

\author{
Ayu Intan Sari ${ }^{1}$, Dewa Ayu Agustini Posmaningsih ${ }^{2}$
}

\begin{abstract}
Garbage is one that affects beach tourism, the problem of cleanliness of garbage seems to be an important problem that must be addressed at the beach. The impact of waste on the environment on the beach can kill coral reefs, marine life, and humans. The condition of the beach tourism environment polluted by garbage will reduce the attractiveness of tourists to visit the beach because it seems dirty The purpose of this study was to determine the knowledge, attitudes and behavior of visitors in waste management at Mertasari beach in 2020. This study used a descriptive method with data collection techniques with questionnaire sheets. The results of the study of visitor's knowledge showed that 28 people (35\%) had poor knowledge in waste management, 22 people (27.5\%) had negative attitudes towards waste management and 28 (35\%) had poor behavior. good in waste management. It is recommended that the manager of Mertasari Beach be expected to collaborate with community leaders to conduct training on waste management, make regulations regarding sanctions if littering.As well as puskesmas and BUMDES in supervision and monitoring, providing health counseling by providing information on waste management by using leaflets, while BUMDES facilitates all needs in an effort to increase knowledge on how to manage waste such as adequate landfills.
\end{abstract}

Keywords: Knowledge, Attitude, Behavior, Waste Management

\section{PENDAHULUAN}

Sampah menjadi salah satu yang mempengaruhi pariwisata pantai, permasalahan kebersihan sampah seakan menjadi masalah penting yang harus ditangani di Pantai. Selain mencemari lingkungan pantai, kenyamanan wisatawan akan sangat tidak baik sehingga mengurangi minat wisatawan akan datang lagi ke pantai. Dampak pencemaran sampah di pantai akan berdampak pada konteks global karena Indonesia merupakan negara kepulauan dengan dikelilingi laut yang sebagian tercemar oleh sampah dari aktifitas manusia yang tentunya akan berakibat pada perairan air laut yang berdampak langsung pada laut samudera dunia yang secara global dengan secara langsung akan ikut tercemar(1).

Pencemaran laut oleh sampah menyebabkan kerusakan ekosistem dan biota laut. Berbagai 
aktifitas manusia menjadi faktor penyebab terjadinya kerusakan ekosistem lingkungan. Untuk memenuhi kebutuhan hidup manusia memerlukan sejumlah kegiatan yang justru berperan dalam kerusakan lingkungan disekitarnya(2)

Hasil penelitian Awaludin mengenai kebersihan di pantai selatan Garut pada tahun 2007 yang menunjukkan bahwa sekitar 65\% sampah yang berada di pesisir pantai tersebut berasal dari pengunjung. Hal ini dikuatkan bahwa sekitar 80\% responden juga menyatakan bahwa kondisi pantai tersebut tidak bersih. Juga telah ditunjukan pada penelitian tersebut bahwa persepsi masyarakat cukup tinggi terhadap kebersihan pesisir sekitar, namun hal ini terkendala oleh kesadaran pengunjung, fasilitas, serta dukungan dari pemerintahan (3)

Sisa sampah yang tidak terangkut akan berpengaruh terhadap kepadatan lalat dapat menjadi tempat perkembangbiakan lalat sehingga dapat meningkatkan tejadinya penyebaran penyakit kepada pengunjung melalui makanan yang telah dihinggapi oleh lalat tersebut sehingga dapat menurunkan keamanan dan kenyamanan pengunjung pantai (4) Sampah di pantai sangat berpengaruh terhadap kesehatan manusia dari kontak langsung benda tajam seperti kaca pecah logam berkarat, dan benda tajam lainnya yang ada di pantai ataupun di dasar perairan(5)

Berdasarkan survei pendahuluan pada 35 responden, diantaranya 16 responden (46\%) yang mengetahui apa dampak membuang sampah sembarangan, 19 responden $(54 \%)$ yang meninggalkan sampahnya begitu saja. Pengetahuan yang dimiliki pengunjung tidak digunakan dengan sebagaimana mestinya, yang mempengaruhi sikap dan perilaku dalam membuang sampah. Hal ini berdasarkan penelitian Posmaningsih menunjukan bahwa ada hubungan pengetahuan dan sikap terhadap partisipasi dalam pengelolaan sampah (6)

Menurut penelitian Surahma (2017), pengetahuan baik dan memiliki perilaku yang tidak baik dalam mengolah sampah disebabkan oleh faktor kurangnya informasi mengenai cara pengolahan sampah yang baik, meskipun seseorang memiliki sikap atau keyakinan yang 
peduli lingkungan namun ketidakadaan informasi itu dapat menyebbabkan orang tersebut tidak dapat bertindak secara efektif pada sikap dan keyakinannya (7). Sikap akan berdampak pada perilaku setiap masyarakat, dengan sikap yang baik diharapkan akan menimbulkan perilaku yang baik walaupun tidak selalu(8) Tujuan dari penelitian ini adalah untuk mnegetahui pengetahuan, sikap dan perilaku pengunjung dalam pengelolaan sampah di Pantai Mertasari Tahun 2020

\section{METODE PENELITIAN}

Jenis penelitian yang digunakan adalah deskriptif dengan pendekatan cross sectional. Tempat penelitian adalah di Pantai Mertasari Desa Intaran, Kelurahan Sanur, Kecamatan Denpasar Selatan dengan waktu penelitian bulan Januari sampai April 2020. Populasi pada penelitian ini tiap bulannya berdasarkan data dari Lurah Desa Sanur Kauh adalah 400 pengunjung, dan sampel pada penelitian ini adalah 80 pengunjung yang melakukan aktivitas di Pantai Mertasari. Pengumpulan data dilakukan dengan menggunakan kuesioner untuk menilai tingkat pengetahuan, sikap dan perilaku pengunjung dalam pengelolaan sampah di Pantai Mertasari. Data yang sudah dikumpulkan dianalisis dan disajikan dalam bentuk tabel atau grafik.

\section{HASIL DAN PEMBAHASAN}

a. Karakteristik responden

Dari 80 responden diperoleh hasil usia yang mendominasi responden adalah 15-29 tahun sebanyak 35 orang (44\%), jenis kelamin yang mendominasi responden adalah laki-laki yaitu 49 orang $(61 \%)$, pendidikan terakhir responden yang paling banyak yaitu SMA atau SMK sebanyak 40 orang (5\%), pekerjaan yang mendominasi adalah swasta yaitu 50 orang $(62,5 \%)$, dan kewarganegaraan yang mendominasi adalah indonesia yaitu 77 orang (96\%).

b. Pengetahuan dan prilaku pengunjung tentang pengelolaan sampah di Pantai Mertasari

Pengetahuan pengunjung tentang pengelolaan sampah di Pantai Mertasari didapatkan hasil bahwa 28 orang (35\%) pengunjung memiliki pengetahuan kurang baik 
dan 52 orang $(65 \%)$ memiliki pengetahuan baik.

Tabel 1

Distribusi frekuensi pengetahuan dengan perilaku pengunjung

Pantai Mertasari Tahun 2020

\begin{tabular}{|c|c|c|c|c|c|c|c|}
\hline \multirow[b]{4}{*}{ Pengetahuan } & \multicolumn{5}{|c|}{ Perilaku } & \multirow{3}{*}{ Total } & \multirow{3}{*}{$\%$} \\
\hline & \multirow[b]{3}{*}{ Kurang Baik } & \multicolumn{2}{|c|}{ Kurang Baik } & \multicolumn{2}{|c|}{ Baik } & & \\
\hline & & $\mathrm{F}$ & $\%$ & $\mathrm{~F}$ & $\%$ & & \\
\hline & & 8 & 28,57 & 20 & 71,43 & 28 & 100 \\
\hline & Baik & 20 & 38,46 & 32 & 61,54 & 52 & 100 \\
\hline \multicolumn{2}{|c|}{ Total } & 28 & 35 & 52 & 65 & 80 & $100 \%$ \\
\hline
\end{tabular}

Dari tabel diatas, responden yang berpengetahuan kurang baik $71,43 \%$ memiliki perilaku baik dan hanya 28,57\% memiliki perilaku kurang baik. Mayoritas responden memiliki pengetahuan baik tetapi memiliki pengetahuan yang tidak baik terhadap pengelolaan sampah. Hal ini dapat disebabkan oleh faktor internal individu yaitu kurangnya kepedulian terhadap kebersihan lingkungan sehingga tidak ada keinginan untuk mengetahui bagaimana perilaku pengolahan sampah yang baik. Tidak semua yang

Pengetahuan dan sikap menurut teori Lawrence Green (1991) adalah faktor predisposisi dalam perubahan perilaku manusia. Faktor predisposisi merupakan faktor yang ada dalam diri seseorang. Pengetahuan akan berperan dalam tindakan yang dilakukannya. Hal ini sesuai dengan hasil penelitian Dewi bahwa memiliki pengetahuan baik akan memiliki perilaku pengelolaan sampah yang baik.

Pengetahuan baik dan memiliki perilaku yang tidak baik dalam pengelolaan sampah disebabkan oleh faktor kurangnya informasi mengenai cara pengelolaan sampah yang baik. Meskipun seseorang memiliki sikap atau keyakinan yang peduli lingkungan namun ketidakadaan informasi keyakinannya. Informasi merupakan faktor yang dapat mempengaruhi pengetahuan seseorang (9)

pengetahuan memberikan pengaruh pada partisipasi masyarakat. Penyebab perubahan perilaku seseorang menjadi ramah lingkungan (pro environmental behavior) adalah informasi yang spesifik ke bidang yang diharapkan. Informasi yang dibutuhkan oleh masyarakat adalah bukan saja hanya informasi yang 
mendorong masyrakat untuk merubah perilaku(10)(11) (9).

Pihak pengelola Pantai Mertasari dapat bekerja sama dengan tokoh masyarakat untuk bekontribusi dalam pengeolaan sampah dengan mampu berperilaku sehat seperti melakukan aksi membuang sampah pada tempatnya dan menarik perhatian pengunjung untuk mau melakukan pengelolaan sampah dengan c. Sikap dan perilaku pengunjung tentang pengelolaan sampah di Pantai Mertasari

Berdasarkan hasil penelitian pengunjung pantai Mertasari yang memiliki sikap negatif yaitu sebanyak 22 orang $(27,5 \%)$ dan 58 (72,5\%). Tabulasi silang sikap dan perilaku pengunjung tentang pengelolaan sampah di Pantai membuat tempat sampah yang unik dan berwarna-warni.

Tabel 2

Distribusi frekuensi sikap dengan perilaku pengunjung tentang pengelolaan sampah di Pantai Mertasari

Perilaku

\begin{tabular}{|c|c|c|}
\hline Kurang Baik & Baik & Tota \\
\hline$\%$ & $\%$ & \\
\hline
\end{tabular}

\begin{tabular}{lrrrrrrr} 
Sikap & Negatif & 7 & $31,8 \%$ & 21 & $36,2 \%$ & 22 & $27,5 \%$ \\
\cline { 2 - 7 } & Positif & 15 & $68,2 \%$ & 37 & $63,8 \%$ & 58 & $72,5 \%$ \\
\hline Total & 22 & $100 \%$ & 58 & $100 \%$ & 80 & $100 \%$ \\
\hline
\end{tabular}

Berdasarkan table 2 diketahui bahwa pada pengunjung yang memiliki perilaku kurang baik $68,2 \%$ memiliki sikap positif

Teori Lawrence Green dalam Notoatmodjo bahwa sikap mempengaruhi perilaku. Dengan demikian untuk mendapatkan sikap yang posiitf dan benar terhadap perilaku membuang sampah, perlu diberikan informasi atau penyuluhan rutin tentang pengelolaan sampah maupun dampak sampah bagi kesehatan dan lingkungan. Peningkatan pemahaman masyarakat tenang pengelolaan sampah dan dampak sampah, akan mewujudkan sikap yang baik terhadap pengelolaan sampah, Pembentukan sikap dipengaruhi oleh beberapa faktor 
yakni pengalaman pribadi, kawasan Pantai Mertasari dengan kebudayaan orang lain yang memberikan informasi tentang dianggap penting, media masa, pengelolaan sampah dan kesehatan lembaga pendidikan dan lembaga agama, dan faktor emosional (12).

Menurut Wardani, sikap atas masalah sampah memberikan pengaruh terhadap partisipasi masyarakat dalam pengelolaan sampah dengan nilai asosiasi 0,428. Timbulnya tanggapan atau respon dari masyarakat untuk berpartisipasi dalam bentuk swadaya, dipengaruhi oleh sikap, persepsi dan pengalamannya. Hasil penelitian Muller tahun 2002 tentang pengelolaan sampah di Nagapura, Bangalore, menyatakan bahwa partisipasi masyarakat tentang pengelolaan sampah rumah tangga akan meningkat seiring dengan meningkatnya kesadaran masyarakat. Penelitian pengelolaan sampah permukiman berbasis masyarakat di Taiwan memper-lihatkan bahwa perilaku masyarakat mendaur ulang sampah dipengaruhi oleh sikap, norma dan perilaku(6) (13)(14)(15)

Sehingga diperlukan pihak Puskesmas dalam pengawasan untuk melakukan pendekatan dengan pemberian penyulahan kesehatan di salah satunya menggunakan media leaflet dan memberikan arahan dan ajakan untuk mendorong pengunjung untuk membuang sampah ditempatnya. Mcluhan mengatakan, medium is a massage, yang berarti ketersediaan tempat sampah (medium) secara tidak langsung memberikan pesan kepada orangorang agar membuang sampah pada tempatnya sehingga lingkungan menjadi bersih dan bebas dari penyakit(9).

Pengujung sebenarnya tidak melakukan perilaku yang baik tetapi mereka tau bahwa perilaku yang baik yang mana, sehingga mereka menjawab perilaku yang benar bukan perilaku yang mereka lakukan. Hal ini sesuai dengan penelitian Fisher tahun 1993, tentang bias keinginan sosial dan validitas pertanyaan tiiak langsung, yaitu jawaban responden dihasilkan dari keinginan responden untuk menghindari rasa malu dan memproyeksikan citra yang baik kepada orang lain(16).

Saat tidak ada keyakinan dalam suatu sikap pengunjung 
tersebut dalam pengelolaan sampah menjadi tidak baik sesuai teori Allport yang menyatakan bahwa sikap suatu perilaku dipengaruhi oleh keyakinan bahwa perilaku tersebut akan membawa kepada hasil yang diinginkan. Keyakinan dan pengalaman seseorang akan terciptanya suatu kondisi lingkungan yang bersih dan sehat melalui pengelolaan sampah. Sikap tumbuh selama manusia hidup sepanjang hidupnya dan manusia tidak pernah berhenti belajar (9).

Sikap yang tidak baik disebabkan oleh kurangnya pengetahuan tentang pengelolaan sampah yang baik. Informasi atau pengetahuan adalah syarat penting bagi sikap. Jadi, sikap bukan hanya perasaan mendukung atau tidak mendukung perilaku, namun juga menyangkut estimasi akan hasil dari perilaku tersebut. Beberapa aspek yang mempengaruhi sikap seseorang terhadap perilaku pengelolaan sampah diantaranya aspek kelembagaan yang menyangkut sarana dan prasarana dan peraturan-peraturan untuk meminimasi perilaku pengelolaan sampah yang tidak baik (9).

\section{SIMPULAN DAN SARAN}

Adapun simpulan dari penelitian ini antara lain:

1. Pengetahuan setiap pengunjung pantai Mertasari dalam pengelolaan sampah dinilai dengan 20 pertanyaan dan didapatkan hasil yaitu sebanyak 28 orang $(35 \%)$ memiliki pengetahuan yang kurang baik dan sebanyak 52 orang $(65 \%)$ memiliki pengetahuan baik.

2. Sikap pengunjung pantai Mertasari dalam pengelolaan sampah dinilai dengan 6 pertanyaan dan didapatkan hasil yaitu sebanyak 22 orang $(27,5 \%)$ memiliki sikap negatif dan sebanyak 58 orang $(72,5 \%)$ memiliki sikap positif.

3. Perilaku pengunjung pantai Mertasari dalam pengelolaan sampah diniali dengan 6 pertanyaan dan didapatkan hasil yaitu sebanyak 28 orang (35\%) memiliki perilaku yang kurang baik dan 52 orang $(65 \%)$ memiliki perilaku yang baik.

Berdasarkan penelitian diatas dapat diberikan saran sebagai berikut:

1. Untuk meningkatkan pengetahuan pengunjung 
diharapkan pengelola Pantai

Mertasari bekerjasama dengan

tokoh masyarakat melakukan

pelatihan-pelatihan tentang

pengelolaan sampah. Dan

membuat peraturan mengenai sanksi jika membuang sampah sembarangan.

2. Untuk meningkatkan kesadaran pengunjung diharapkan Puskesmas serta BUMDES dalam pengawasan dan pemantauan, memberikan penyulahan kesehatan dengan memberikan informasi tentang pengelolaan sampah dengan menggunnakan leaflet, sedangkan BUMDES memfasilitasi seluruh kebutuhan dalam upaya peningkatan pengetahuan cara pengelolaan sampah seperti tempat pembuangan sampah yang cukup.

3. Untuk mewujudkan kebersihan dan kenyamanan Pantai Mertasari diharapkan kepada pengunjung ikut serta menjaga kebersihan dikawasan pantai dengan menerapkan aturan larangan membuang sampah sembarangan di kawasan Pantai Mertasari.

\section{DAFTAR PUSTAKA}

1. Ningsih RW. Dampak

Pencemaran Air Laut Akibat

Sampah Terhadap Kelestarian

Laut Di InDonesia. 2015;1-

12.

2. Lingkungan DK. Social

Responsibility. 2016;203-225.

3. Awaluddin MY. Introduksi

konsep bersih pantai (coastal

cleanup) di pantai

Sindangkerta, kecamatan

Cipatujah, Kabupaten

Tasikmalaya . Harpodon

Borneo. 2011;4(2):38-43.

4. Dewantara SAAG,

Posmaningsih DAA, Notes N.

"Gambaran Pengelolaan

Sampah Di Kawasan Wisata

Pantai Sanur Tahun 2016.”

Jurnal Skala Husada 7: 2-3. J

Skala Husada. 2017;7.

5. Yuliadi LPS, Nurruhwati I,

Astuty S. Optimalisasi

Pengelolaan Sampah Pesisir

Untuk Mendukung Kebersihan

Lingkungan Dalam Upaya

Mengurangi Sampah Plastik

Dan Penyelamatan Pantai 
Pangandaran. J Pengabdi Kpd

Masy. 2017;1(1):14-8.

6. Posmaningsih DAA. Faktor-

Faktor Yang Mempengaruhi

Partisipasi Masyarakat Dalam

Pengelolaan Sampah Padat Di

Denpasar Timur. J Skala

Husada [Internet].

2016;13(1):59-71. Available

from:

https://www.kesling.poltekesd

enpasar.com

7. Sari N, Mulasari SA.

Pengetahuan, Sikap dan

Pendidikan dengan Perilaku

Pengelolaan Sampah di

Kelurahan Bener Kecamatan

Tegalrejo Yogyakarta. J Med

Respati [Internet].

2017;12(2):74-84. Available

from:

http://eprints.uad.ac.id/8012/1/

30-55-1-SM.pdf

8. Sudiharti, Solikhah. Hubungan

Pengetahuan Dan Sikap

Dengan Perilaku Perawat

Dalam Pembuangan Sampah

Medis Di Rumah Sakit PKU

Muhammadiyah Yogyakarta.

Kes Mas J Fak Kesehat Masy

Univ Ahmad Daulan.

2012;6(1):1-74.
9. Notoatmodjo S. Promosi

Kesehatan Teori dan

Apklikasi. 1st ed. Jakarta:

Rineka Cipta; 2010. 50-60 p.

10. Astari SD, Warmadewanthi I.

Kajian Model Pengelolaan

Sampah Berbasis Masyarakat

Di Kecamatan Wonocolo Kota

Surabaya. Pros Semin Nas

Manaj Teknol IX. 2010;

11. Gardner GT, Stern PC.

Environmental Problems and

Human Behaviour. A Simon

\& Schuster Company.

Massachusets. 1996.

12. Notoatmodjo S. Pendidikan

Dan Perilaku Kesehatan.

Jakarta: Rineka Cipta; 2003.

13. Tamond ZE. Partisipasi

Masyarakat dan Teknik

Pengelolaan Sampah di

Pemukiman. Vol.1 (4) Juni : J

Formas. 2008;1(4 Juni):277-

83.

14. Fatin $\mathrm{S}$ et all. A Review On

The Succes Factors For

Community Participation In

Solid Waste Management.

Penang. Malaysia: Proceeding

of Inter- national Conference

On Manage- ment (ICM

2011). 2011; 
15. Wardani C. Partispasi

Masyarakat Pada Kegiatan

Pemilahan Sampah Rumah

Tangga. Universitas

Indonesia.; 2004.

16. Fisher JR. Bias Keinginan

Sosial dan Validitas

Pertanyaan Tidak Langsung. J

Penelit Konsum [Internet].

1993;2:330-5. Available

from:

https://acdemic.oup.com/jcr/ar

ticle-

abstract/20/2/30/1793106. 